\title{
Egg shape in the Common Guillemot Uria aalge and Brunnich's Guillemot $U$. lomvia: not a rolling matter?
}

\author{
Tim R. Birkhead ${ }^{1}$ (D) Jamie E. Thompson ${ }^{1} \cdot$ John D. Biggins $^{2}$
}

Received: 21 September 2016/Revised: 9 November 2016/ Accepted: 21 December 2016

(c) The Author(s) 2017. This article is published with open access at Springerlink.com

\begin{abstract}
The adaptive significance of avian egg shape is poorly understood, and has been studied only in those species producing pyriform (pear-shaped, or pointed) eggs: waders and guillemots (murres) Uria spp., albeit to a limited extent. In the latter, it is widely believed that the pyriform shape has evolved to minimise their likelihood of rolling off a cliff ledge: the idea being that the more pointed the egg, the narrower the arc in which it rolls, and the less likely it is it will fall from a cliff ledge. Previous research also claimed that the rolling trajectory-the diameter of the arc they describe-of Common Guillemot $U$. aalge eggs is influenced not only by its shape but also by its mass, with heavier (i.e. larger) eggs describing a wider arc than lighter eggs. The finding that both shape and mass determined the rolling trajectory of Common Guillemot eggs (the shape-mass hypothesis) was used to explain the apparent anomaly that Brünnich's Guillemot $U$. lomvia produce eggs that are less pointed, yet breed on narrower ledges than Common Guillemots. They are able to do this, it was suggested, because Brünnich's Guillemot eggs are smaller and lighter in mass than those of Common Guillemots. However, since some populations of
\end{abstract}

Communicated by F. Bairlein.

Electronic supplementary material The online version of this article (doi:10.1007/s10336-017-1437-8) contains supplementary material, which is available to authorized users.

Tim R. Birkhead

t.r.birkhead@sheffield.ac.uk

1 Department of Animal and Plant Sciences, University of Sheffield, Sheffield S10 2TN, UK

2 School of Mathematics and Statistics, University of Sheffield, Sheffield S10 2TN, UK
Brünnich's Guillemots produce eggs that are as large or larger than those of some Common Guillemot populations, the shape-mass hypothesis predicts that that (1) larger (i.e. heavier) eggs of both guillemot species will be more pyriform (pointed) in shape, and (2) that eggs of the two species of same mass should be similarly pointed. We tested these predictions and found: (1) only a weak, positive association between egg volume and pointedness in both guillemot species $(<3 \%$ of the variation in egg shape explained by egg volume), and (2) no evidence that eggs of the two species of similar mass were more similar in shape: regardless of their mass, Brunnich's Guillemot eggs were less pointed than Common Guillemot eggs. Overall, our results call into question the long-held belief that protection from rolling is the main selective factor driving guillemot egg shape.

Keywords Common Murre $\cdot$ Thick-billed Murre $\cdot$ Egg shape $\cdot$ Pyriform $\cdot$ Egg mass $\cdot$ Adaptive significance

\section{Zusammenfassung}

Die Eiform bei Trottel- und Dickschnabellumme (Uria aalge, U. lomvia): Wirklich ein Schutz vor dem Wegrollen?

Inwieweit die Form von Vogeleiern eine Anpassung darstellt, ist bislang kaum untersucht; am ehesten noch bei den Arten, die pyriforme bzw. spitzpolige Eier legen, nämlich Schnepfenvögel und Lummen (Uria-Arten). Im Fall der Lummeneier wird allgemein angenommen, dass die spitze Eiform als Schutz vor dem Wegrollen von Simsen bzw. Felsbändern entstanden ist: Je spitzer die Eier seien, um so enger der Bogen, den sie beim Rollen beschreiben. Das reduziere das Risiko, von schmalen 
Felsbändern herunterzufallen. Frühere Untersuchungen gingen davon aus, dass die Rollrichtung der Eier (d. h. der Durchmesser des Bogens, den die Eier beschreiben) bei Trottellummen ( $U$. aalge) nicht nur von der Eiform, sondern auch von der Masse beeinflusst wird, wobei schwerere (also größere) Eier einen weiteren Bogen nehmen als leichtere. Die Tatsache, dass bei Trottellummen sowohl Form als auch Masse eines Eies die Rollrichtung vorgeben (die sog. Eiform- und Eimassenhypothese) wurde wiederholt bei der Diskussion der scheinbaren Regelabweichung herangezogen, dass Dickschnabellummen ( $U$. lomvia) weniger spitze Eier als Trottellummen legen, obwohl sie auf noch schmaleren Felsbändern als letztere brüten. Dies sei deshalb möglich, weil die Eier von Dickschnabellummen kleiner und leichter als die von Trottellummen seien. Allerdings gibt es Populationen von Dickschnabellumme, die gleichgroße Eier wie Trottellummeneier oder sogar noch größere Eier legen. Die bereits erwähnte Eiform- und Eimassenhypothese sagt voraus, dass (1) die größeren (und damit schwereren) Eier beider Lummenarten eine spitzere Form haben und (2) gleich schwere Eier bei beiden Arten eine ähnlich spitze Form aufweisen sollten. Diese Voraussagen wurden von uns überprüft: (1) Es existiert eine schwache, positive Korrelation zwischen Eivolumen und Spitzpoligkeit bei beiden Lummenarten (weniger als $3 \%$ der Variation der Eiform werden vom Eivolumen erklärt). (2) Es gibt keine Evidenz, dass bei beiden Arten gleichschwere Eier eine höhere Formähnlichkeit aufweisen. Unabhängig von ihrer Masse waren Dickschnabellummeneier weniger spitz als Trottellummeneier. Damit stellen unsere Ergebnisse die langgehegte Vorstellung in Frage, dass ein Wegrollschutz den wichtigsten Selektionsfaktor bei der Entstehung der Eiform von Trottelllummen darstellt.

\section{Introduction}

The adaptive significance of avian egg shape is poorly understood (Barta and Székely 1997) and, except for those species producing pyriform (pear-shaped, or pointed) eggs such as waders and guillemots (murres) Uria spp., little studied. In waders, Andersson (1978) found that a pyriform egg allows females to maximise egg volume in a four-egg clutch while simultaneously maximizing the area in contact with the parents' brood patch during incubation. For the Common Guillemot Uria aalge and Brünnich's Guillemot U. lomvia, the pyriform (pear-shaped) shape of their single egg has long been considered an adaption to minimise the risk of rolling off the narrow cliff ledges on which these species typically breed (MacGillivray 1852; Belopol'skii
1957; Del Hoyo et al. 1996; Gill 2007; reviewed in Birkhead 2016).

In support of this hypothesis, it has been shown that the guillemots' pyriform eggs tend to roll in an arc, whereas the 'elliptical-ovate' egg of the closely related Razorbill Alca torda - which breeds as pairs in cavities with little risk of the egg falling - rolls in a much wider arc (Belopol'skii 1957; Ingold 1980). Using plaster model eggs of different shapes, Tschanz et al. (1969) also showed that the more pointed the egg, the tighter the arc, and-presumably-the greater the protection conferred. However, Ingold (1980) subsequently showed that the plaster eggs used in Tschanz et al. (1969) study did not behave in the same the way as real eggs, and that, contrary to expectation, there was little difference in the rolling trajectories of real Common Guillemot and Razorbill eggs on natural substrates. Ingold (1980) concluded that: 'It has to remain unanswered whether the form of the guillemot egg [has] evolved in response to the pressure of the risk of falling off.' (translated from German).

Ingold (1980, 2016), however, has presented some evidence that the guillemot's pyriform egg still confers an advantage with respect to rolling. First, he found that, when comparing eggs of the same mass, the pyriform Common Guillemot eggs rolled in a slightly smaller arc than the elliptical-ovate Razorbill eggs ( $n=9$ for each species). Second, heavier (and thus larger) Common Guillemot eggs $(n=9)$ rolled in a wider arc than lighter eggs. Thus, the arc described by a rolling guillemot egg depends on both its shape and mass. Consequently, he argued that, because Common Guillemot eggs are larger (and therefore heavier) than Razorbill eggs, they would roll in an even wider arc and be especially vulnerable to falling if they were the same elliptical-ovate shape as Razorbill eggs.

Ingold (1980) further suggested that this interplay between shape and mass in determining an egg's rolling arc might also explain the anomaly that Brünnich's Guillemots produce eggs that are less pointed than those of Common Guillemots (Belopol'skii 1957; Harris and Birkhead 1985; Birkhead and Nettleship 1987b), even though Brünnich's Guillemots typically lay on narrower cliff ledges (Birkhead and Nettleship 1987a), and their eggs are therefore even more vulnerable to being lost by falling than Common Guillemot eggs. Ingold's (1980) explanation was that, because Brünnich's Guillemot eggs are smaller and lighter in mass than those of Common Guillemots', they can afford to be less pointed because lighter eggs roll in a smaller arc.

Ingold (1980) did not comment on the fact that some populations of Brünnich's Guillemots produce eggs that are as large or larger than those of some populations of Common Guillemot (e.g. Harris and Birkhead 1985). His hypothesis-that shape and mass together determine an 
egg's rolling trajectory-would therefore predict (1) that in both guillemot species, larger (i.e. heavier) eggs will be more pyriform or pointed in shape, and (2) that eggs of the two species of same mass should be pointed to a similar extent.

The aim of the present study was to test these two predictions, as an indirect test of the idea that the pyriform shape of guillemot eggs has evolved to minimise the risk of falling off cliff ledges.

\section{Methods}

Our measure of guillemot egg shape was the same as that used by Belopol'skii (1957) and Harris and Birkhead (1985): the proportion of overall egg length between the egg's widest point and its more pointed end. We call this measure 'pointedness', although Deeming and Ruta (2014) refer to it as the 'asymmetry ratio'. While there have been numerous efforts to characterise the shape of birds' eggs (see Deeming and Ruta 2014; Mityay et al. 2015 for further references), there is as yet no single parameter that adequately captures the degree to which eggs are pyriform in shape. We have not used Deeming and Ruta's (2014) principle component analyses to characterise shape in this present study because the principle component they use to describe shape (PC2) is closely correlated with our measure of pointedness (defined above).

We obtained pointedness measurements from photographs of eggs, taken under standardised conditions, from museum collections and from the field (see Online Resource 1, Sect. 1 for further details), and we additionally used these photographs to compute egg volume (see Online Resource 1, Sect. 1 for further details), which we used as a proxy for mass since the two variables [i.e. egg volume and egg mass (of both fresh and pipping eggs)] are highly correlated (Birkhead and Nettleship 1984). Specifically, for Common Guillemot fresh eggs: $r=0.967, n=37$; for pipping eggs, $r=0.826, n=86$; and for Brünnich's Guillemots fresh eggs: $r=0.952, n=78$; for pipping eggs, $r=0.848, n=66$; all $p<0.001$ (Birkhead and Nettleship 1984: table VI). There was no difference in the density of eggs weighed within $24 \mathrm{~h}$ of laying between the two guillemot species (see Online Resource 1, Sect. 2).

Some populations of guillemots differ in both body size and absolute egg size (Harris and Birkhead 1985: pp. 168-174) and our original objective was to compare egg shape between and within populations of both Uria species. A simulation suggested that a sample of around 50 eggs from one population (colony) is needed to capture most of the variation in shape (results not shown); however, few museum collections had such large numbers of eggs from single locations. We therefore pooled samples for all locations for each species and compared the relationship between shape and volume and for each species separately. Only for Common Guillemots were there sufficient eggs (from three geographically distinct locations) to compare colonies: Skomer Island, Wales, UK, Bempton, Yorkshire, UK and Hjelmsoy (Hjelmsøya), Finnmark, Norway.

We also explored the relationship between egg shape and volume in more detail using a unique collection of eggs from a single colony (Bempton, Yorkshire, UK) that included unusually small ('dwarf') and unusually large ('doubled-yolked') eggs as well as 'normal' eggs (see Online Resource 1, Sect. 3 for further details).

Finally, we compared the shape of 78 eggs laid by 34 different females within and between years, to examine the consistency of shape within females (using the intraclass correlation coefficient; Lessells and Boag 1987; Nakagawa and Schielzeth 2010; see Online Resource 1, Sect. 4 for further details). Using eggs from Skomer Island, where we had measured and photographed both a haphazard sample of 210 eggs and 19 pairs of first and replacement eggs, we ran four different simulations of 100,000 replications each to compare the intraclass correlation between (1) random permutations of the replacement egg values, (2) a random selection of 19 eggs from other (i.e. non-replacement) Skomer eggs to pair with the first eggs, (3) 19 pairs drawn at random from other Skomer eggs, and (4) 19 pairs of eggs formed from other Skomer eggs, with the selection biased to mimic the approximately $5 \%$ volume difference observed (see Birkhead and Nettleship 1984) between first and replacement eggs.

\section{Results}

The rolling-in-an-arc hypothesis predicts that larger eggs of both guillemot species should be more pointed than smaller eggs. We tested this using data from 732 Common Guillemot eggs and 259 Brünnich's Guillemot eggs. Although pointedness increased significantly with egg volume, the slope of the relationship, which did not differ between the two species, was relatively shallow (Fig. 1). Moreover, egg volume explained just 0.5 and $2.7 \%$ of the variation in pointedness in the Common Guillemot and Brünnich's Guillemot, respectively (Fig. 1). This result provides only very weak support for the first hypothesis.

As previous studies have shown, the eggs of Brünnich's Guillemots are significantly less pointed than those of the Common Guillemot (e.g. Birkhead and Nettleship 1987b), but in our sample, there was no significant difference in mean egg volume between the two species (Fig. 1). Critically for Ingold's hypothesis, the eggs of Brünnich's Guillemot are less pointed than those of the Common 


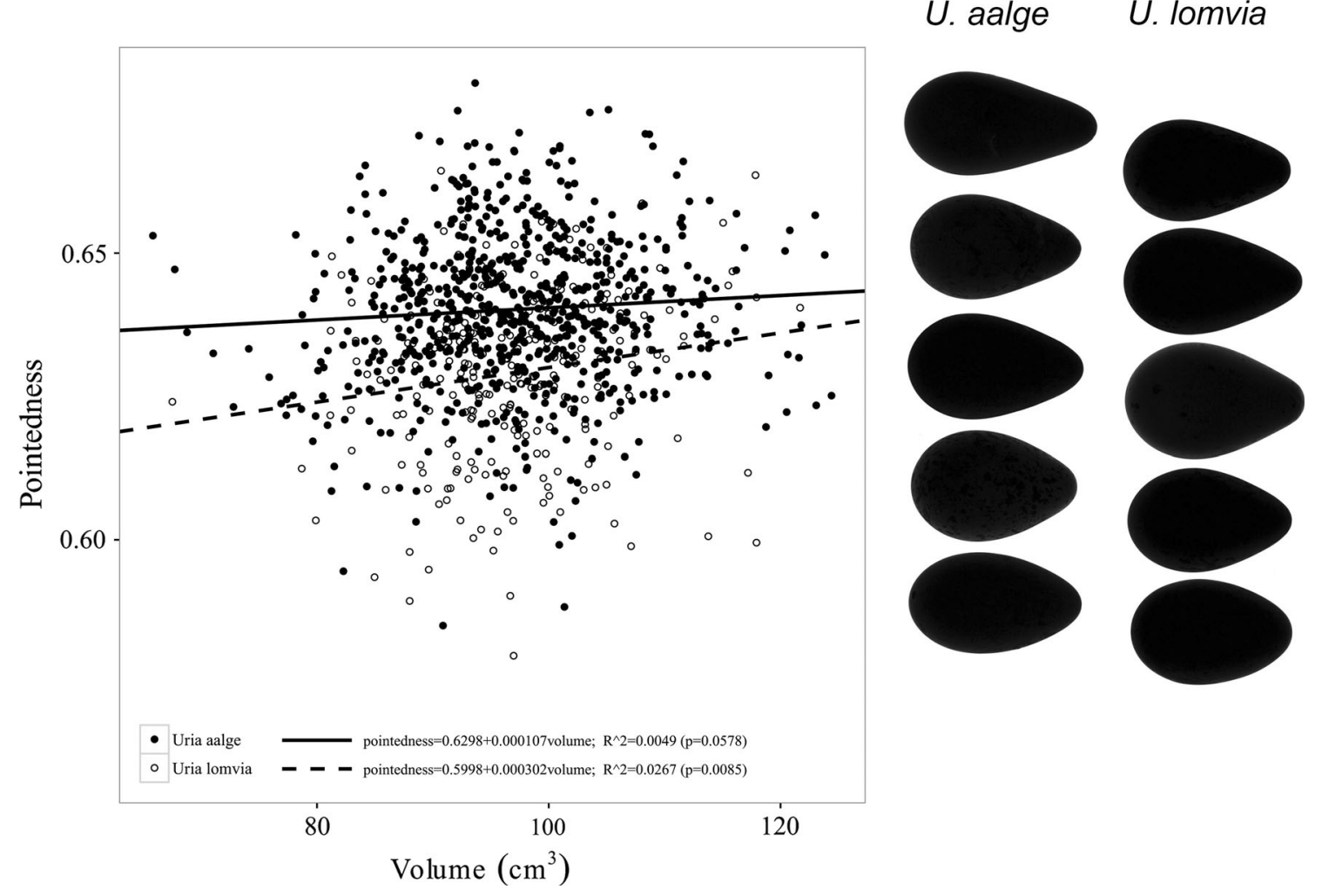

Fig. 1 Relationship between pointedness and egg volume $\left(\mathrm{cm}^{3}\right)$ for eggs of Common Guillemot Uria aalge (filled circles; $n=732$ ) and Brünnich's Guillemot $U$. lomvia (open circles; $n=259$ ). Using ANCOVA, the two slopes are not significantly different $(t=1.603$, $d f=987, p=0.109)$ and, dropping this the interaction term, the common slope differs significantly from zero $(t=2.963, d f=988$, $p=0.0032$ ). Egg volume does not differ significantly between species (Welch's $t=0.3364, d f=498, p=0.74$ ); means: $U$. aalge

Guillemot (Fig. 1) after controlling for egg volume, a result that also provides no support for the rolling-in-an-arc hypothesis.

A possible explanation for the slight increase in pointedness with volume is that the female's oviduct constrains the maximum egg diameter such that eggs that have a larger volume are longer by necessity. We explored this hypothesis in three ways. First, we looked at the relationship between volume and pointedness within colonies. This showed that, while the volume of Common Guillemot eggs differed significantly between the three geographic locations as expected (because of geographical differences in body mass; see Tuck 1961), shape did not (Fig. 2).

Second, comparing the shape of atypically small, atypically large eggs and 'normal' Common Guillemot eggs from a single colony, we found that large-volume, doubleyolked eggs were significantly more pointed, and dwarf eggs significantly less pointed than 'normal' eggs (Fig. 3). This is consistent with the idea that egg volume plays a role in determining egg shape.
97.06, $U$. lomvia 96.86, 95\% CI for difference $(-0.96,1.36)$. However, pointedness differed markedly between species (Welch's $t=10.63, d f=420, p<0.001)$, with $U$. aalge eggs being more pointed; means: $U$. aalge $0.640, U$. lomvia $0.629,95 \% \mathrm{CI}$ for difference $(0.009,0.013)$. On the right are examples of eggs (to scale, within the volume range $95-105 \mathrm{~cm}^{3}$ ), of both species, representing the different values of pointedness, aligned with the $y$ axis

Third, comparing the shape of eggs laid by the same female, either within a season (first vs. replacement eggs) or between seasons (first eggs), we found high and significant repeatability in egg shape (between $r=0.705$ and 0.921 , for different datasets; all $p<0.001$ ), demonstrating a strong female effect (see Online Resource 1, Sect. 4 for further details). For first and replacement eggs from Skomer, the intraclass correlation coefficient value was 0.825 , a value that exceeded the maximum obtained in four different simulations (see "Methods") in every one of the 100,000 replicates per simulation $(p<0.00001)$.

\section{Discussion}

We found that egg volume (equivalent to mass) explained less than $3 \%$ of the variation in shape, and hence constitutes only very weak evidence for the hypothesis that larger (i.e. heavier) guillemot eggs are more pointed than lighter ones. In other words, since over $97 \%$ of the variation in egg shape is unexplained, size clearly has little effect on egg 
Fig. 2 Relationship between egg volume and pointedness of eggs from Common Guillemot Uria aalge populations at a Skomer Island, Wales $(n=210)$, b Bempton, Yorkshire, UK $(n=83)$, and c Hjelmsoy (Hjelmsøya), Finnmark, Norway $(n=136)$. The slopes do not differ significantly $\left(F_{(2,423)}=0.11\right.$, $p>0.8)$ and their common value differs significantly from zero $\left(t_{425}=3.6, p<0.001\right)$, with $3.5 \%$ of the total variation in shape explained by egg volume. Pointedness does not differ significantly between colonies $\left(F_{(2,426)}=1.16\right.$, $p>0.3)$ but egg volume does $\left(F_{(2,426)}=69.2, p<0.0001\right)$
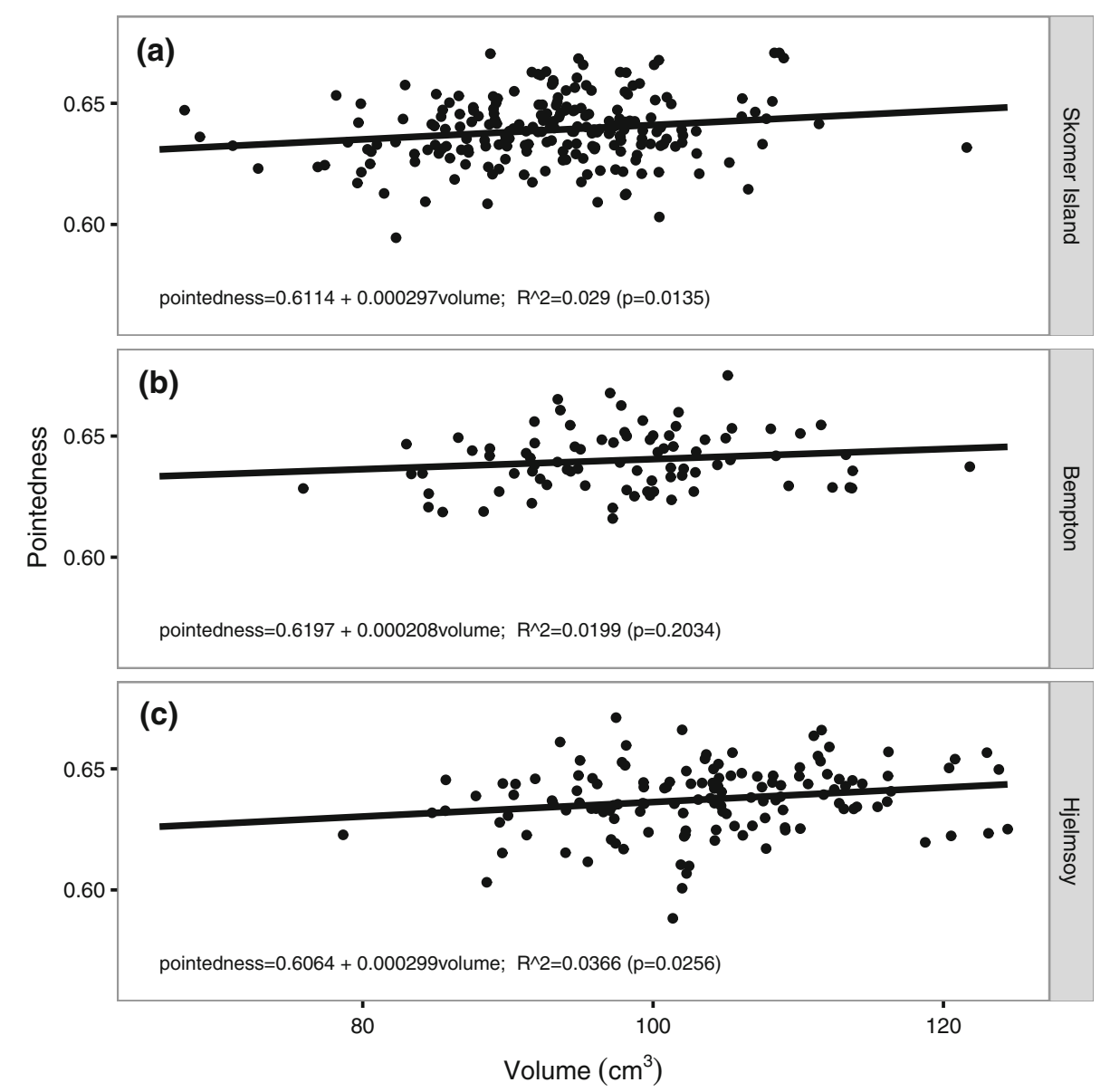

shape. A more plausible explanation for the slight positive relationship between volume and pointedness is that egg shape becomes slightly more pyriform as size increases as a result of some constraint on maximum egg diameter within the oviduct.

More critically, even after controlling for egg size, the eggs of Brünnich's Guillemot are less pointed than those of the Common Guillemot. Brünnich's Guillemots breed on much narrower ledges than Common Guillemots, and therefore if egg shape is an adaptation to facilitate rolling in an arc, we expect Brünnich's Guillemot eggs to be more pointed, not less, than those of Common Guillemots. Our result thus provides no support for the idea that guillemot egg shape is an adaptation to minimise the risk of rolling.

The factors influencing how the avian oviduct determines the shape of eggs are not well known. Egg shape is likely determined by the eggshell membrane before the shell is formed, and that membrane is formed within the isthmus region of the oviduct. It is assumed that one end of this region is more constricted as the membrane is being formed (Bradfield 1951; Smart 1991). In addition, it is known that egg length and breadth (diameter) in particular are consistent within female birds (Romanoff and Romanoff 1949), including guillemots and the Razorbill
(Birkhead and Nettleship 1984). Here, we show that egg shape within females, at least for Common Guillemots, is also repeatable, although the reasons for this are unknown.

It is striking that, with very few exceptions, almost all previous researchers have attempted to explain the pyriform shape of guillemot eggs as an adaptation to minimise the risk of rolling (Belopol'skii 1957; Tschanz et al. 1969; Ingold 1980). This narrow focus may be a consequence of the way guillemot colonies were studied and exploited during most of the twentieth century. In the past, those collecting eggs or studying guillemots typically climbed onto breeding ledges causing the incubating birds to depart in panic, and many of their eggs rolled off the ledge (Belopol'skii 1957; Uspenski 1956; Tuck 1961). Some studies even looked at the effect of gunshots, which caused an immediate mass departure of incubating birds in panic and a concomitant loss of eggs (Belopol'skii 1957). All this suggested that egg loss through rolling must be a major mortality factor for breeding guillemots. More recent observational studies of undisturbed guillemots showed that it is relatively rare for an egg to roll off a ledge (Birkhead 1977; Harris and Wanless 1988). Unless disturbed by large terrestrial predators such as man, guillemots of both species rarely leave their egg unattended: one 


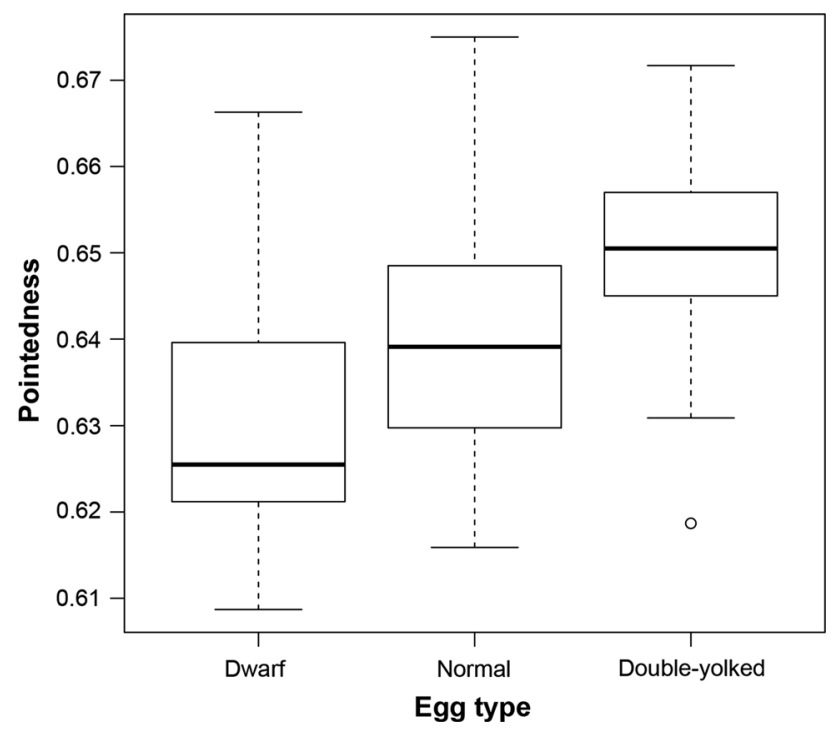

Fig. 3 Variation in pointedness for Common Guillemot Uria aalge dwarf eggs $\left(n=13\right.$; mean egg volume $\mathrm{cm}^{3} \pm 95 \% \quad \mathrm{CL}$ : $58.49 \pm 2.58)$, normal eggs $(n=83 ; 97.95 \pm 1.79)$ and doubleyolked eggs $(n=37 ; 142.40 \pm 2.41)$ previously collected from a single colony found at Bempton, Yorkshire, UK. Pointedness (mean $\pm 95 \% \quad$ CL): $\quad$ dwarf $=0.631 \pm 0.009$; nor$\mathrm{mal}=0.640 \pm 0.003, \quad$ and $\quad$ double-yolked $=0.650 \pm 0.003$, (ANOVA $F_{(2,130)}=14.86, p<0.0001$; Tukey posthoc comparisons: dwarf vs. double yolk $(p<0.001)$; normal vs. double yolk $(p<0.001)$; normal vs. dwarf $(p<0.05))$. Boxes are the interquartile range, black line within the box is the median, the whiskers show the highest and lowest values and open circles indicate potential outliers

partner incubates continuously. Escaping from predators that threaten their own life and abandoning their egg is exactly what we might expect from a long-lived species like guillemots.

Ingold's $(1980,2016)$ conclusion that both shape and mass affect an egg's rolling trajectory is based on a rather small sample size ( $n=9$ Common Guillemot and $n=9$ Razorbill eggs). Also, as we show in this present study, eggs of the same volume or mass can vary considerably in shape (Fig. 1), but Ingold provides no information on egg shape, nor does he tell us whether he even matched eggs of similar mass in his rolling experiments. Third, as had been shown previously and confirmed by his own studies, egg mass declines during the course of incubation, yet he does not state that the eggs used in these experiments were at the same stage of incubation. With at least three different factors affecting an egg's rolling trajectory, Ingold's (1980) sample size of 9 is almost certainly too low to draw any firm conclusions.

Ingold (1980) acknowledged that other selection pressures, such as 'weather conditions, predators and conspecifics', might explain the pyriform shape of the Common Guillemot's egg, but he did not elaborate nor test any other hypotheses. He also showed that parental behavior, including keeping the egg between their legs with the blunt end directed away from the bird, was important in keeping the egg on the ledge (Ingold 1980; see also Tschanz 1990; Ingold 2016). Elsewhere, we consider several other hypotheses for the pyriform shape of guillemot eggs (Birkhead et al. 2017).

Acknowledgements TRB conceived the project. TRB and JET collected the data; JET and JDB analysed the data; and TRB wrote the manuscript. We thank the following museum curators for allowing us to examine their eggs: Jean Woods (Delaware Natural History Museum, USA), Douglas Russell (Natural History Museum at Tring, UK), Rob Barrett (Tromsø Zoology Museum, Norway), Henry McGhie, (Manchester University Museum, UK), Brian Schmidt (Smithsonian Institute Washington, US), Jon Fjeldsa (Natural History Museum of Denmark), Ingvar Byrkjedal (University Museum of Bergen, Norway), Julian Carter (National Museum of Wales, UK) and Dan Gordon (Tyne and Wear Archives and Museums, UK). Mark Hipfner kindly provided the data that allowed us to calculate the density of fresh guillemot eggs. The translation of Ingold (1980) was made by Claudius Kerth. We thank Nicola Hemmings, Paul Ingold, Duncan Jackson, Bob Montgomerie, Julie Riordan, Tony Ryan and Karl Schulze-Hagen for valuable discussion. Thanks also to The Wildlife Trust of South and West Wales for permission to work on Skomer Island, and to the wardens there (Birgitta Büche and Edward Stubbings) for their help. We are grateful to Duncan Jackson and Bob Montgomerie for comments on the manuscript. The study was funded in part by a grant (to TRB) from the Leverhulme Trust, to whom we are very grateful. This work was carried out in compliance with the current laws in the United Kingdom.

Open Access This article is distributed under the terms of the Creative Commons Attribution 4.0 International License (http://crea tivecommons.org/licenses/by/4.0/), which permits unrestricted use, distribution, and reproduction in any medium, provided you give appropriate credit to the original author(s) and the source, provide a link to the Creative Commons license, and indicate if changes were made.

\section{References}

Andersson M (1978) Optimal egg shape in waders. Ornis Fenn 55:105-109

Barta Z, Székely T (1997) The optimal shape of Avian eggs. Funct Ecol 11:656-662

Belopol'skii LO (1957) Ecology of sea colony birds of the Barents Sea. Israel Program for Scientific Translations, Jerusalem (Translated from Russian 1961)

Birkhead TR (1977) The effect of habitat and density on breeding success in the Common Guillemot Uria aalge. J Anim Ecol. 46:751-764

Birkhead TR (2016) The most perfect thing: the inside (and outside) of a bird's egg. Bloomsbury, London

Birkhead TR, Nettleship DN (1984) Egg size, composition and offspring quality in some Alcidae (Aves: charadriiformes). J Zool Lond 202:177-194

Birkhead TR, Nettleship DN (1987a) Ecological relationships between Common Murres, Uria aalge and Thick-billed Murres, Uria lomvia, at the Gannet Islands, Labrador. II: breeding success and site characteristics. Can J Zool 65:1630-1637

Birkhead TR, Nettleship DN (1987b) Ecological relationships between Common Murres, Uria aalge and Thick-billed Murres, Uria lomvia, at the Gannet Islands, Labrador. I: morphometrics and timing of breeding. Can J Zool 65:1621-1629 
Birkhead TR, Thompson JE, Jackson D, Biggins JD (2017) The point of a guillemot's egg. Ibis. doi:10.1111/ibi.12458

Bradfield JRG (1951) Radiographic studies on the formation of the hen's eggshell. J Exp Biol 28:125-140

Deeming DC, Ruta M (2014) Egg shape changes at the theropod-bird transition, and a morphometric study of amniote eggs. R Sci Open Sci. doi:10.1098/rsos.140311

Del Hoyo J, Elliot A, Sartgatal J (1996) Handbook of the birds of the world, vol 3. Lynx, Barcelona

Gill F (2007) Ornithology. Freeman, New York

Harris MP, Birkhead TR (1985) Breeding ecology of the Atlantic Alcidae. In: Nettleship DN, Birkhead TR (eds) The Atlantic Alcidae. Academic, London, pp 155-205

Harris MP, Wanless S (1988) The breeding biology of guillemots Una aalge on the Isle of May over a six year period. Ibis 130:172-192

Hewitson WC (1831) British Oology: being illustrations of the eggs of British birds. Empson, Newcastle upon Tyne

Ingold P (1980) Anpassungen der Eier und des Brutverhaltens von Trottelummen an das Brüten auf felssimen. Z Tierpyschol 53:341-388

Ingold P (2016) Brüten an Felsklippen-was Trottellummen (Uria aalge ualgebefühigt, auf Felssimsen und in dichten Gemeinschaftenzu brüten. Orn Beob 113:85-120
Lessells CM, Boag PT (1987) Unrepeatable repeatabilities: a common mistake. Auk 104:116-121

MacGillivray W (1852) A History of British Birds. Scott, Webster and Geary, London

Mityay IS, Matsyura AV, Jankowksi K (2015) Application of bird egg morphometrics in phylogeny. Acta Biol Sib 1:92-102

Nakagawa S, Schielzeth H (2010) Repeatability for Gaussian and non-Gaussian data: a practical guide for biologists. Biol Rev 85:935-956

Romanoff AJ, Romanoff AL (1949) The avian egg. Wiley, New York Smart IHM (1991) Egg-shape in birds. In: Deeming DC, Ferguson MJW (eds) Egg incubation: its effects on embryonic development in birds and reptiles. Cambridge University Press, Cambridge, pp 101-116

Tschanz B (1990) Adaptations for breeding in Atlantic Alcids. Neth J Zool 40:688-710

Tschanz B, Ingold P, Lengacher H (1969) Eiform und Bruterfolg bei Trottellummen. Ornithol Beob 66:25-42

Tuck LM (1961) The Murres: their distribution, populations and biology - a study of the genus Uria. Can Wildl Monogr Ser 1:260

Uspenski SM (1956) Bird bazaars of Novaya Zemlya. Canadian Wildlife Service translations of Russian game reports, vol 4. CWS, Ottawa (Translated from Russian 1958) 